\title{
Research on the Entrepreneurial Intention for Students Polytechnic based on Association Analysis
}

\author{
Yinzhen Zhong ${ }^{1, a}$, Ye Cao ${ }^{1, b}$, Haohang Huang ${ }^{2, c}$, Wuxue Jiang ${ }^{2, d}$ \\ ${ }^{1}$ Department of Finance, Dongguan Polytechnic, Dongguan 523808, Guangdong, China \\ ${ }^{2}$ Department of Computer Engineering, Dongguan Polytechnic, Dongguan 523808, Guangdong, China \\ azhongyz@dgpt.edu.cn, bye1315607143@qq.com, ${ }^{\mathrm{c}} 280934652 @ q q . c o m,{ }^{d}$ jiangwx@dgpt.edu.cn
}

\begin{abstract}
The entrepreneurial intention and influencing factors for students in Dongguan Vocational Colleges were analyzed with the PCA (principal component analysis) and sequence logistics model based on the survey data from eight vocational colleges in Dongguan, the basic situation, prominent problems and policy suggestions for the college students' entrepreneurial intention were researched, and the results showed that the entrepreneurial education and students' potential influenced the entrepreneurial intention significantly, the professional category influenced obviously, and the origin of students had a certain influence. The corresponding countermeasures and suggestions were proposed from the perspectives of the government, school and student according to the influencing status.
\end{abstract}

Keywords: Association analysis; Apriori; Vocational college; Entrepreneurial intention

\section{Introduction}

Implementation Opinion to Deepen the Reform of Innovative Entrepreneurship Education in the Universities and Colleges was issued by the General Office of the State Council in May, 2015, which allowed the college students to conduct the innovative entrepreneurship at the temporary absence from school while remaining the enrollment, required to implement the employment promotion and entrepreneurship leading plan for the graduates from colleges and universities, and drive the employment entrepreneurship. Along with the development of national innovative entrepreneurship strategy and the promotion of entrepreneurship education of college students, the entrepreneurship for the college students has become a vital part of the national innovative entrepreneurship, and the entrepreneurship has gradually become a kind of career choice for the college students and graduates. As the demonstration city of domestic innovative entrepreneurship, Dongguan City has issued Implementation Opinion to Promote the Employment Entrepreneurship for Graduates from Dongguan Universities and Colleges and other series of policies to provide the whole-process service and tracking guidance for the college students' entrepreneurship employment via College Student Entrepreneurship Preferential Policy, Dongguan Innovative Entrepreneurship Talent Service Center, Dongguan Maker Union, "Winning in Dongguan" Innovative Entrepreneurship Science and Technology Competition and other standing agencies and normal activity platforms, stimulate the college students' innovative entrepreneurship consciousness, improve the success rate of entrepreneurship in the colleges and students, and promote the reform of entrepreneurship education. Dongguan Polytechnic has clearly proposed to deepen the promotion of innovative entrepreneurship education reform, implement Action Plan to Deepen the Reform of Innovative Entrepreneurship Education, fully update the education concept, set up the compulsory course of innovative entrepreneurship, integrate the innovative entrepreneurship education into the professional teaching and cultivate the talents with technical skills in the 13th Five-Year Development Plan. The Leading Group for Innovative Entrepreneurship Work has been established to promote the innovative entrepreneurship education, and support the students' entrepreneurship from the site, fund and policy and others.

\section{Association mining algorithm}


Definition of association rule mining: a transaction data set of $\mathrm{T}$ was offered, and the association rule on all support $>=$ min_support and confidence $>=$ min_confidence was found.

1) The frequent item set was generated

All item sets meeting the minimum support were found at the stage, and those found item sets were called as frequent item set.

2) Generation rule

The rules meeting the minimum confidence were generated based on the frequent item set at the previous step, and the generating rules were called as the strong rules. The time cost on the association rule mining was mainly on the generation of frequent item set, for there were a few frequent item set to be found, it did not take too much time to generate the rule via frequent item set, while various alternative item sets shall be tested to generate the frequent item set, and the needed time was $\mathrm{O}\left(2^{\wedge} \mathrm{N}\right)$ if not optimized.

3) Classical association rule mining algorithm- Apriori algorithm

Apriori algorithm is the most widely used algorithm for the database association rule mining, and the algorithm efficiency influences the generation of auditing rule, the efficiency and accuracy of the auditing and other problems directly. There are two obvious deficiencies for Apriori algorithm: one is the algorithm efficiency is reduced due to the frequent scanning of database; and the other is the algorithm efficiency is reduced due to the mode matching adopted by the algorithm to identify the frequent item set.

4) Improved optimization algorithm adopted in the paper

The new data structure was taken, and the improved algorithm used the child brothers based on the tree to represent the data structure:

typedef struct transaction

\{

Long tid;

Struct transaction * next;

\}transaction;

Typedif struct nodel

\{

Char item;

Int level, intSumSupport;

Struct node *pParent, *pFirstChild, *pNextSibling;

Transaction *pTransacrion;

\}node;

Among the improved optimization algorithm, each brother node was arranged in parallel, each child had a pointer to the parent node, one scanning was only needed for the database or data warehouse, thus avoiding the multiple scanning on database among Apriori algorithm, reducing the huge I/O expenditure, and improving the performance of the system.

\section{Analysis method}

The sequential logistic model was used to analyze the factors influencing the college students' entrepreneurial intention and behavior. Simply, two dichotomy logistic models were estimated at the same time, whether there was the entrepreneurial intention was analyzed in the first model, and those entrepreneurial intention transforming the entrepreneurial behavior finally were further analyzed among the samples with the entrepreneurial intention in the second model. However, compared with two independent dichotomy logistic models, the parameter estimation and hypothesis test in sequence logistic model were conducted at the same time, so that the model did not only have the flexibility of model setting, but also have the high efficiency of statistical test, therefore, it was suitable to reply to the problems researched in the paper. 


\section{Analysis result}

1. The college students had a higher entrepreneurial intention, while they took less entrepreneurial action

The investigation results have shown that the college students' entrepreneurial intention in Dongguan universities and colleges surpassed 30\%, and the strength of entrepreneurial intention was above average, which was a gratifying results for the current transformation and upgrade of Dongguan industry, for the college students can drive the employment market on the one hand as an important subject of innovative entrepreneurship, on the other hand, the entrepreneurship can promote the research of new technology, new product and new service, and the development of creative thinking, and further strengthen the good atmosphere of "public entrepreneurship and mass innovation". However, the investigation results showed that only $12.2 \%$ selected the campus entrepreneurship, and $37.7 \%$ did not have the specific entrepreneurship time as shown in Fig.1.

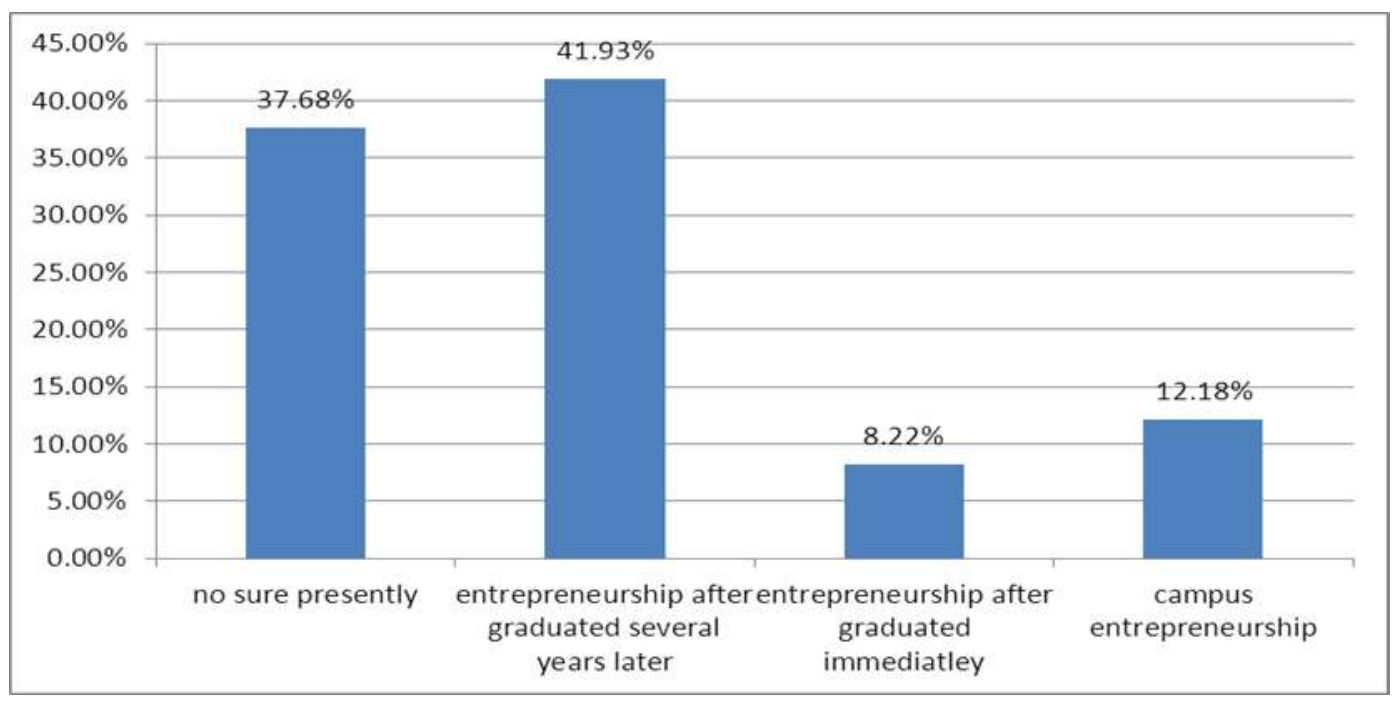

Fig.1 scale distribution of entrepreneurship at different times,

2. The entrepreneurship curriculum setting was insufficient, and it was hard to cultivate the college students to improve the entrepreneurship quality and ability

The setting of entrepreneurship curriculum content shall focus on the ratio of entrepreneurship knowledge and quality, and the perfect entrepreneurship course shall systematically teach students about the entrepreneurship knowledge system and fully improve the students' entrepreneurship quality. However, the current entrepreneurship curriculum in Dongguan universities and colleges failed to distinguish with the traditional economic management curriculum on the teaching of entrepreneurship knowledge, even these two were confused, some even can not be mentioned with the colleges having advanced entrepreneurship education at home and abroad. Students can not learn the needed knowledge for entrepreneurship, and the entrepreneurial ability was hard to improve. Moreover, the teaching on the theoretical knowledge related with the entrepreneurship was concerned greatly, while the cultivation of entrepreneurial quality was neglected.

3. There were obvious disadvantages on the fund, knowledge, experience and others, and the entrepreneurial intention was influenced directly

The fund, knowledge and experience were key factors on the entrepreneurship success. However, the college students were receiving the higher education, the knowledge structure related with the entrepreneurship was incomplete, the economic independence was not obtained completely, and the necessary social experience was lacked, therefore, the college students had the natural disadvantages on the above three aspects. It was a vital difference in the entrepreneurship process between the college students and other social groups, thus directly making the college students were confronted with more disadvantages and difficulties in entrepreneurial practice. The entrepreneurship guidance, fund support and political support shall be offered targeted concerning the feature of the college students to promote 
the success of the entrepreneurship practice.Main influence aspects of entrepreneurship and its influence degree are shown in Fig.2.

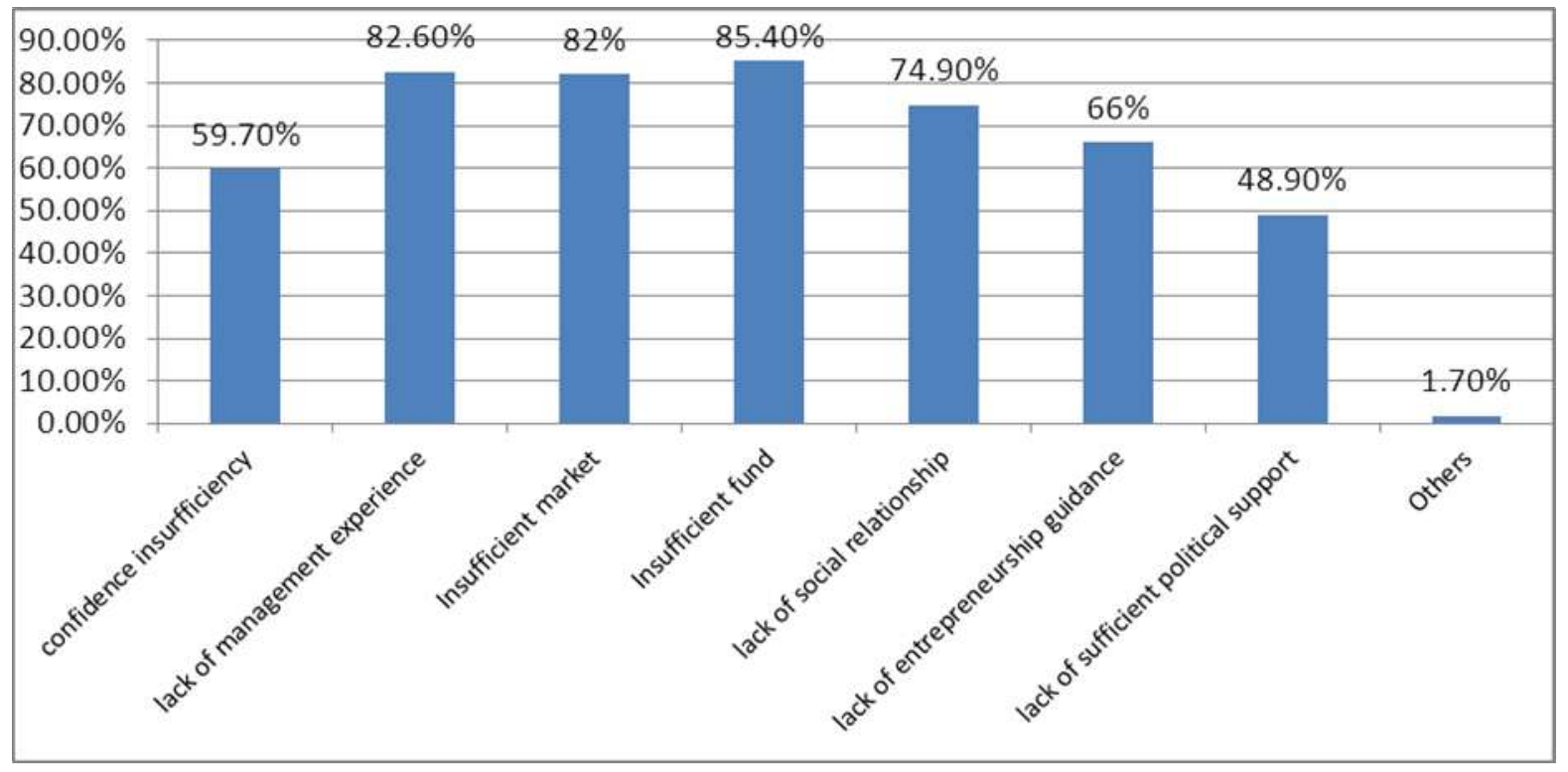

Fig.2 main difficulties faced for the entrepreneurship of college students

4. The preparation of entrepreneurial knowledge was not positive, and it was hard to guarantee the demand of entrepreneurship

The college students shall make the necessary knowledge preparation for entrepreneurship via various learning opportunities, or improve own entrepreneurial ability via some training or exercise opportunities for there is the natural disadvantage on the fund, knowledge, experience and others. The investigation results showed that only 382 respondents attending the entrepreneurship training or lecture accounting for $40.4 \%$, only 84 respondents attending the college students' entrepreneurship competition accounting for $8.9 \%, 282$ respondents taking the curriculum related with entrepreneurship accounting for $29.8 \%$. The ratio that the college students having the entrepreneurial intention made the preparation was not too high. Only $46.6 \%$ college students having the entrepreneurial intention attended the entrepreneurship training or lecture, $35.7 \%$ took the related entrepreneurship curriculum, and $10.9 \%$ attended the college students' entrepreneurship competition. Therefore, it can be seen that although the college students had a higher entrepreneurial intention, they lacked the entrepreneurship knowledge, and they can not make the necessary knowledge reserve for the entrepreneurship actively. It was easy that the college students found the severe lack of necessary industrial experience, management skill and key technology and other operation knowledge after throwing into the entrepreneurship chamber with the enthusiasm, the entrepreneurship was relatively difficult for sustainability and success, specific information is shown in Table 1.

Table 1. knowledge preparation for entrepreneurship

\begin{tabular}{|c|c|c|c|c|}
\hline & & \multicolumn{2}{|c|}{ whether there is a willingness } & total \\
\hline & & no & yes & \\
\hline \multirow{4}{*}{$\begin{array}{l}\text { whether attended } \\
\text { entrepreneurship } \\
\text { seminar or training }\end{array}$} & no & $376(63.2 \%)$ & $187(53.4 \%)$ & $563(100 \%)$ \\
\hline & yes & $219(36.8 \%)$ & $163(46.6 \%)$ & $382(100 \%)$ \\
\hline & total & 595 & 350 & \\
\hline & & $(100.0 \%)$ & $(100.0 \%)$ & \\
\hline \multirow{4}{*}{$\begin{array}{l}\text { whether participated in } \\
\text { the college student } \\
\text { entrepreneurship } \\
\text { competition }\end{array}$} & no & $549(92.3 \%)$ & $312(89.1 \%)$ & $861(100.0 \%)$ \\
\hline & yes & $46(7.7 \%)$ & $38(10.9 \%)$ & $84(100.0 \%)$ \\
\hline & total & 595 & 350 & \\
\hline & & $(100.0 \%)$ & $(100.0 \%)$ & \\
\hline \multirow{4}{*}{$\begin{array}{l}\text { whether studied } \\
\text { entrepreneurship } \\
\text { courses }\end{array}$} & no & $438(73.6 \%)$ & $225(64.3 \%)$ & $663(100.0 \%)$ \\
\hline & yes & $157(26.4 \%)$ & $125(35.7 \%)$ & $282(100.0 \%)$ \\
\hline & total & 595 & 350 & \\
\hline & & $(100.0 \%)$ & $(100.0 \%)$ & \\
\hline
\end{tabular}




\section{Countermeasures and suggestions}

1. Functional government departments

1)The functional government departments shall establish and perfect the related entrepreneurship policy and increase the supporting dynamics. Seen from the current entrepreneurship policy documents in Dongguan city and each neighborhood, the graduates and employment difficulty groups are the main objects of the policy. Dongguan Human Resource Bureau and related functional departments in the neighborhood are suggested to contain the college students in the entrepreneurship supporting objects, aim at the key entrepreneurship crowd among the college students, increase the supporting dynamics, find out and incubate the outstanding college students' entrepreneurship projects, ensure to fully practice the college students' outstanding entrepreneurship project during the campus period, guarantee the continuous entrepreneurship after graduation, and improve the sustainability of entrepreneurship project to help promote the college students' entrepreneurship project.

2)The functional government departments shall strengthen the advertising work of entrepreneurship policy and promote the college students' understanding on the entrepreneurship policy

It is necessary to strengthen the advertising work of college students' entrepreneurship policy for many college students having the entrepreneurial intention do not understand the entrepreneurship policy and the enjoyed political preference. The advertising department shall attach great importance to the propaganda work of college students' entrepreneurship in Dongguan, firmly grasp the correct direction of public opinion, use the network, TV and other carriers and forms to advertise the new trend and impetus of college students' entrepreneurship in Dongguan. For example, Dongguan has set "3W Coffee", "Wanglai Coffee" and "Honeycomb Coffee" and other entrepreneurship cafes.

2. Institutions of higher learning

1)The institutions of higher learning shall guide the college students to develop the correct entrepreneurship view, and carry out the entrepreneurship education targeted for different groups. Firstly is to provide the basic education of universal entrepreneurship for all college students, let them know the value and purpose of the college students' entrepreneurship, help them conduct the entrepreneurship orientation, and clearly know whether they have the entrepreneurship potential. Secondly is to let the university student having powerful entrepreneurial intention and certain entrepreneurship potential establish the lofty ideal of entrepreneurs, and the entrepreneurship education shall mainly focus on the knowledge and operation of industrial development trend, start-up fund obtaining, registration of company, product's market positioning and others. Thirdly is to provide the specialized entrepreneurship education for the college students having started own business, which is mainly to teach how to manage the enterprise, mitigate the risk, strive for the venture capital and others.

2)The institutions of higher learning shall optimize the setting of entrepreneurship curriculum, and treat the entrepreneurship quality and knowledge equally. The entrepreneurship curriculum in the universities and colleges are mainly teaching the entrepreneurship knowledge and cultivating the entrepreneurship quality for college students to improve their entrepreneurial ability and provide the entrepreneurship possibility for their long-term development. Firstly is to innovate the passenger-car form and improve the college students' creative quality. Organizing the college students' entrepreneurship salon, inviting the small and medium-sized entrepreneurs and others to conduct the face-to-face communication with the college students, feeling the entrepreneurial character, belief, spirit and feelings, causing their yearning for entrepreneurship, and eliminating their fear for the entrepreneurship can stimulate the great appeal and demonstration to encourage the college students to be brave on the entrepreneurship and grow up healthily. Secondly is to increase the dynamics of entrepreneurship practice and expand the education space. The space of entrepreneurship education shall be expanded to the inside and outside of the classroom, book and school to achieve the combination of theoretical teaching and practical teaching, teaching inside and outside of the campus and social practice and practical training, dominant curriculum and hidden curriculum.

3. College students 
1)The college students shall actively reserve the entrepreneurship knowledge and improve the entrepreneurship quality

Actively attending the entrepreneurship education and practical activity for the college students having the entrepreneurial intention can fill in the gap targeted and perfect own entrepreneurship knowledge structure system via the learning of entrepreneurship curriculum on the one hand. On the other hand, it can also improve the entrepreneurship skill and cultivate the qualities needed for the entrepreneurship via the entrepreneurship competition, post internship, experience exchange and other entrepreneurial practical activities.

2)The college students shall actively concern the dynamics of entrepreneurship policy and link up the entrepreneurship resources

The college students having the entrepreneurial intention shall also actively concern the national, provincial and municipal entrepreneurship policies, especially the political dynamics on the college students' entrepreneurship in Dongguan city and each neighborhood. Actively concerning the political dynamics can help strive for more entrepreneurship resource on the one hand. On the other hand, it can also help understand the industrial demand of local economic development, aim at the market demand, and be favorable for the entrepreneurship orientation. Firstly, the college students shall actively concern the official website of related functional government departments to timely get the latest political information. Secondly, they shall exchange with other more entrepreneurship agencies, functional departments and entrepreneurs via various entrepreneurship communication platforms to learn the experience. Thirdly, they shall attend various entrepreneurship practical activities to know the political dynamics and get the entrepreneurship resources in practice.

\section{Acknowledgements}

This work was financially supported by Guangdong college students' science and technology innovation cultivation project in 2018(No. pdjhb0903), and by the fund project of Dongguan Polytechnic (No.2016c02), and by the project of Guangdong higher vocational entrepreneurship education teaching steering committee (No.cyqn2017002).

\section{References}

[1] Teixeira Sergio Jesus, Casteleiro Carla Maria Lopes, Rodrigues Ricardo Gouveia, Guerra Maria Dulce. Entrepreneurial intentions and entrepreneurship in European countries. International Journal of Innovation Science, 1, pp. 22-42, 2018.

[2] Al-Shammari Minwir, Waleed Rana. Entrepreneurial intentions of private university students in the kingdom of Bahrain. International Journal of Innovation Science, 1, pp. 43-57, 2018.

[3] Jiang WuXue, Zhong YinZhen, Liang Huan. An Evaluation Model of Polytechnic Teaching Quality Based on ID3 Decision Making Tree. Applied Mechanics and Materials, 651-653, pp. 2437-2440, 2014.

[4] Mortara Letizia, Parisot Nicolas Gontran. Through entrepreneurs' eyes: the Fab-spaces constellation.International Journal of Production Research, 23, pp. 7158-7180, 2016.

[5] Eom Mike Tae-in. How Can Organization Retain IT Personnel? Impact of IT Manager's Leadership on IT Personnel's Intention to Stay. Information Systems Management, 4, pp. 316-330, 2015.

[6] Jiang WuXue, Zhong YinZhen, Cao WenLiang, Li ShuFei. An Improved Virtualization Resource Migration Strategy and Its Application in Data Center. Advances in Intelligent Systems and Computing, 541, pp. 213-218, 2017. 